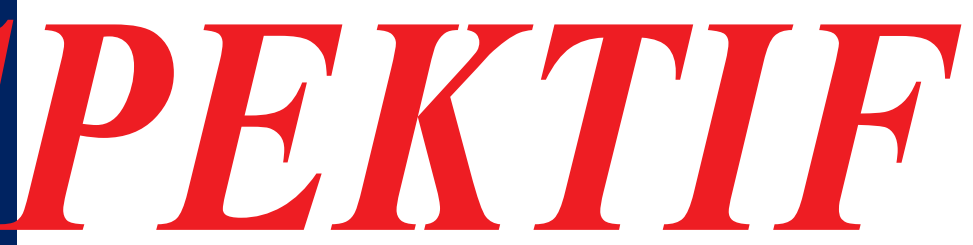

\title{
DAFTAR ISI
}

MODEL OF SHARIA PRINCIPLES INTEGRATION

IN THE APLLICATION OF CAPITAL MARKET LAW

Desy Nurkristia Tejawati dan Fries Melia Salviana

PEMISAHAN JABATAN PEJABAT UMUM DI INDONESIA

Fayakundia Putra Sufi dan Rusdianto Sesung .....

TINDAK PIDANA CYBERPORN DALAM KAJIAN

YURIDIS UNDANG-UNDANG PORNOGRAFI

Ferry Irawan Febriansyah

PERLINDUNGAN HUKUM TERHADAP ANAK SEBAGAI PENYALAHGUNA NARKOTIKA DALAM SISTEM PERADILAN PIDANA ANAK DI INDONESIA

Beni Harmono Harefa

KEDUDUKAN AHLI WARIS TERHADAP HARTA WARISAN SESEORANG YANG DIDUGA MENINGGAL DUNIA (KEADAAN TIDAK HADIR)

Haryadi Sutanto dan Henny Tanuwidjaja

KAJIAN TERHADAP FAKTOR-FAKTOR PENYEBAB

KECELAKAAN LALU LINTAS DALAM UPAYA PERBAIKAN

PENCEGAHAN KECELAKAAN LALU LINTAS

Umi Enggarsasi dan Nur Khalimatus Sa'diyah

PERLINDUNGAN HUKUM TERHADAP AHLI WARIS YANG MEMPEROLEH WARISAN TANAH ABSENTEE 


\section{EDITORIAL TEAM \\ JURnal PERSPEKTIF}

\section{Editor in Chief:}

Besse Sugiswati

Managing Editor:

Ari Purwadi

\section{Board of Editors:}

Ahmad Basuki

Birkah Latif

(Wijaya Kusuma Surabaya University)

(Hasanuddin University)

Faizal Kurniawan (Airlangga University)

Fajlurrahman Jurdi (Hasanuddin University)

Joko Nur Sariono (Wijaya Kusuma Surabaya University)

Mispanyah (Lambung Mangkurat University)

Muhamad Azhar (Diponegoro University)

Otong Rosadi (Ekasakti University)

Sri Susyanti Nur (Hasanuddin University)

\section{Assistant Editors:}

Fani Martiawan Kumara Putra

Ria Tri Vinata

\section{Board of Administration:}

Desy Nurkristia Tejawati

Nur Khalimatus Sa'diyah

\section{Publisher:}

Institution For Research and Community Services (LPPM)

of Wijaya Kusuma Surabaya University

Address of The Editorial Board:

\section{Jurnal PERSPEKTIF}

Faculty of Law, Wijaya Kusuma Surabaya University, Building A $1^{\text {st }}$ Floor

JI. Dukuh Kupang XXV/54 Surabaya 60225 Telp. (031) 5677577 Pesawat 152 Fax: (031) 5679791

e-mail: perspektif_hukum@yahoo.com Homepage: http://jurnal-perspektif.org

Indexed by:

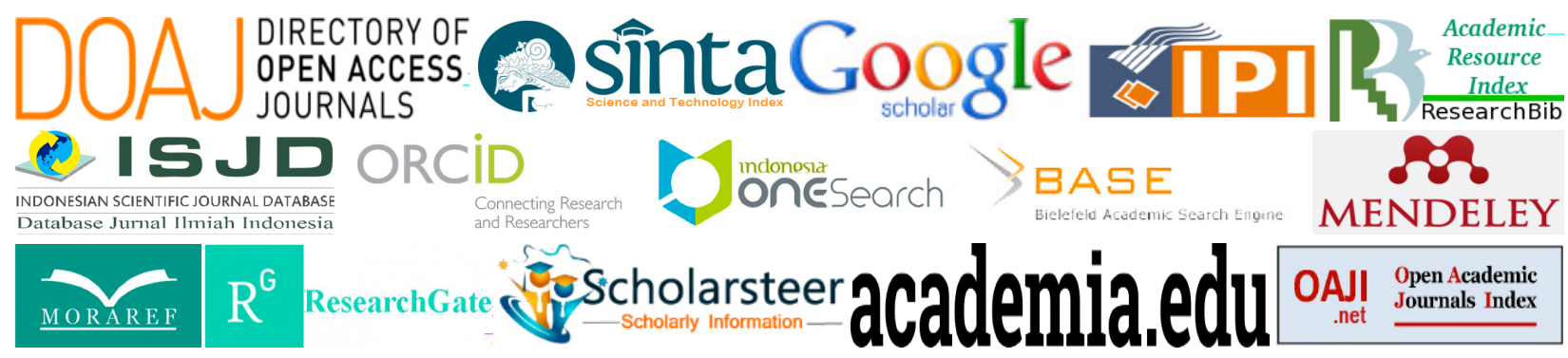

